\title{
Involvement of the Sarcoplasmic Reticulum Calcium Pump in Myocardial Contractile Dysfunction: Comparison between Chronic Pressure-overload and Stunning
}

\author{
Hari S. Sharma, ${ }^{1,2}$ Pieter D. Verdouw, ${ }^{I}$ \\ and Jos M.J. Lamers ${ }^{3}$ \\ Experimental Cardiology, Thoraxcenter, ${ }^{1}$ Department of \\ Pharmacology ${ }^{2}$ and Biochemistry ${ }^{3}$ (Cardiovascular Research \\ Institute COEUR). Faculty of Medicine and Health Sciences. \\ Erasmus University Rotterdam, Rotterdam. The Netherlands
}

\begin{abstract}
Summary. Acute as well as chronic forms of heart failure involve mechanical dysfunction during systole and/or diastole. The rapid $\mathrm{Ca}^{2+}$ release from and $\mathrm{Ca}^{2+}$ reuptake into the tubuli of the sarcoplasmic reticulum are processes that critically determine normal systolie and diastolic myocardial function, which explains why in the last fifteen years so much attention has been paid to understand the performance of the sarcoplasmic reticulum $\mathrm{Ca}^{2+}$ pump during myocardial contractile dysfunction. In this communication we have reviewed the literature data on sarcoplasmic reticulum $\mathrm{Ca}^{2+}$ pump function in the chronically pressure-overloaded hypertrophied and stunned (post-ischemic reversibly injured) myocardium in the light of some new data from our laboratory. Results on the pressure-overloaded hypertrophied myocardium provide evidence that impaired relaxation is most likely due to a low capacity of the sarcoplasmic reticulum to pump $\mathrm{Ca}^{2+}$, a consequence of a lower density of $\mathrm{Ca}^{2+}$-pumping sites within the sarcotubular membranes. Contractile dysfunction in stunned myocardium is accompanied by an upregulation of the sarcoplasmic reticulum $\mathrm{Ca}^{2+}$ ATPase gene resulting in a slight increase of the $\mathrm{Ca}^{2+}$ pumping activity. The latter increase is likely an adaptive response of the reversibly injured myocardium which may contribute to the slow recovery of contractile function.
\end{abstract}

Cardiovasc Drugs Ther 1994;8:461-468

Key Words. sarcoplasmic reticulum, $\mathrm{Ca}^{2+}$ pump, hypertrophy, stunning, cardiac failure

Normal systolic and diastolic function of the heart requires the release and reuptake of $\mathrm{Ca}^{2+}$. The contractile state of the heart can be altered by two mechanisms which are both $\mathrm{Ca}^{2+}$ dependent: changes in the availability of $\mathrm{Ca}^{2+}$ to the contractile proteins and changes in the responsiveness of the contractile proteins to activation by intracellular $\mathrm{Ca}^{2+}[1]$. The availability of intracellular $\mathrm{Ca}^{2+}$ is regulated by the sarcolemma (SL) and sarcoplasmic reticulum (SR) and the $\mathrm{Ca}^{2+}$ responsiveness is controlled by the myofilaments and regulatory troponin-tropomyosin complex. Exci- tation-contraction (E-C) coupling is initiated when $\mathrm{Ca}^{2+}$ channels are opened by depolarization of SL permitting $\mathrm{Ca}^{2+}$ to enter the cytoplasm. This small $\mathrm{Ca}^{2+}$ influx induces the release of a much larger quantity of activated $\mathrm{Ca}^{2+}$ from the intracellular stores in the SR $[2,3]$. The released $\mathrm{Ca}^{2+}$ interacts with troponin $\mathrm{C}$, which is part of the regulatory complex of the myofilaments, thereby initiating cardiac contraction. Relaxation starts when $\mathrm{Ca}^{2+}$ is sequestered by the $\mathrm{SR}$ $\mathrm{Ca}^{2+}$ pump, so that $\mathrm{Ca}^{2+}$ dissociates from the contractile apparatus.

Abnormal handling of intracellular $\mathrm{Ca}^{2+}$ at any of the steps in $\mathrm{E}-\mathrm{C}$ coupling can cause cardiac contractile dysfunction and leads to failure. The signalling function of $\mathrm{Ca}^{2+}$ demands a very low ionic concentration of $\mathrm{Ca}^{2+}$ inside the myocardial cells (about 10,000 fold lower than outside) and significant changes can therefore be achieved easily. During each depolarization only a very small amount of $\mathrm{Ca}^{2+}$ entering the cell needs to be extruded to prevent $\mathrm{Ca}^{2+}$ overloading of the myocytes [2]. The bulk of $\mathrm{Ca}^{2+}$ released from the SR must be reuptaken to its site of origin (SR) in order to be released during the next cardiac cycle. Several transport systems, including the SR $\mathrm{Ca}^{2+}$ pump, have now been documented in heart membranes. These systems are based on 4 basic transport modes: 1) ATP driven (SL and SR $\mathrm{Ca}^{2+}$ pumps); 2) $\mathrm{Na} / \mathrm{Ca}^{2+}$ antiporters (SL and mitochondria);3) $\mathrm{Ca}^{2+}$ channels (SL and SR) and 4) $\mathrm{Ca}^{2+}$ uniporter (mitochondria) [4]. These systems have either a low or a high $\mathrm{Ca}^{2+}$ affinity, thus serving different purposes in

Address for correspondence: Prof. Dr. P.D. Verdouw, Experimental Cardiology, Thoraxcenter, Erasmus University Rotterdam, P.O. Box 1738, 3000 DR Rotterdam, The Netherlands.

Received 16 November 1993, accepted in revised form 10 January 1994. 
the various phases of the cardiac cycle. Overall, the SR $\mathrm{Ca}^{2+}$ pump can be considered to be the transport system that presides over the rapid and fine regulation of intracellular $\mathrm{Ca}^{2+}$ linked to the contraction/ relaxation cycle.

Acute and chronic forms of heart failure involve mechanical dysfunction during systole and/or diastole $[1,9]$. Following a brief period of myocardial ischemia, insufficient to cause cell death, myocardial function may remain depressed for several hours to days ("myocardial stunning"), which is a form of reversible myocardial dysfunction. Among the cellular organelles whose altered function might account for the contractile dysfunction are the SR, the contractile filaments and the SL. To date the results of several studies point toward a decrease in the responsiveness of the myofilaments for $\mathrm{Ca}^{2+}$ and/or lack of $\mathrm{Ca}^{2+}$ available from SR as primary cause of the abnormal E-C coupling in "stunned" myocardium [5-7]. On the other hand, myocardial hypertrophy, which is one of the most important responses of the heart to chronic pressure-overloading, is an adaptive process that enables the heart to compensate for the decrease in cardiac performance. Cells of the hypertrophied, failing myocardium are not normal $[1,8,9]$, however, and it is now apparent that hypertrophy of the overloaded heart is a complex process that ultimately becomes detrimental after initially exerting a beneficial effect. Disturbed relaxation in early experimental cardiac hypertrophy has been noted for some time [9], but it is not until the last decade that the importance of relaxation abnormalities was clearly demonstrated in patients with congestive heart failure [11]. A slower rate of the SR $\mathrm{Ca}^{2+}$ pump can explain the impaired relaxation in the hypertrophied heart, but an increase in diastolic stiffness by spontaneous recycling of $\mathrm{Ca}^{2+}$ in the $\mathrm{SR}$ during diastole must also be considered [8].

\section{SR $\mathrm{Ca}^{2+}$ Pump Characteristics of the Normally Functioning Myocardium}

SR membranes contain a $\mathrm{Ca}^{2+}$ stimulated $\mathrm{Mg}^{2+}$ dependent ATPase, which represents up to $90 \%$ of the total protein of the membrane, and which transports $\mathrm{Ca}^{2+}$ from the cytosol into the vesicles of the SR with a high velocity and affinity for $\mathrm{Ca}^{2+}$. If one takes the total amount of SR in the heart and combines it with its transport characteristics, it is clear that the amount of $\mathrm{Ca}^{2+}$ needed for the cardiac contraction/ relaxation cycle can be adequately met by the organelle $[2,4]$. The pump protein with a molecular weight of about $115 \mathrm{kDa}$, is distributed asymmetrically across the membrane and consists of dimers of a single polypeptide. For each mole of ATP hydrolyzed, two $\mathrm{Ca}^{2+}$ ions are transported into the SR vesicles. Until recent years the major problem regarding the SR function in the entire cardiac cycle was the not yet known mechanism by which $\mathrm{Ca}^{2+}$ is released from the $\mathrm{SR}$ in the heart. The pieces of the machinery that couple depolarization to $\mathrm{SR} \mathrm{Ca}^{2+}$ release, in particular the isolation of the SR $\mathrm{Ca}^{2+}$ release channel of $565 \mathrm{kDa}$ molecular weight, have now been identified during recent years [3]. At present, it is believed that the capacity of SR to actively take up $\mathrm{Ca}^{2+}$ is present throughout the cardiac cycle. Initially, the small amount of $\mathrm{Ca}^{2+}$ entering the cell during depolarization triggers a transient release of $\mathrm{Ca}^{2+}$ to exceeding the $\mathrm{SR} \mathrm{Ca}^{2+}$ pumping rate (Figure 1). When the intracellular free $\mathrm{Ca}^{2+}$ rises to saturating $\mathrm{Ca}^{2+}$ levels which are sufficient for the activation of myofilaments, the $\mathrm{SR} \mathrm{Ca}^{2+}$ release channel becomes inactivated [2]. Phospholamban, which is an integral membrane protein of cardiac SR, modulates the $\mathrm{Ca}^{2+}$ pump function of cardiac SR [12-14]. When phosphorylated by cyclic AMP-dependent protein kinase or by $\mathrm{Ca}^{2+}$-calmodulin dependent kinase, phospholamban stimulates the $\mathrm{Ca}^{2+}$ pump ATPase, predominantly by increasing the affinity for $\mathrm{Ca}^{2+}$. Phospholamban has been purified and its primary structure has been determined by cDNA cloning and sequencing [14]. It consists of five identical monomers of $5.2 \mathrm{kDa}$ and the stoechiometric ratio between phospholamban pentamer and $\mathrm{Ca}^{2+}$ pump ATPase is about 1 [14]. Phosphorylation of phospholamban relieves its inhibitory effect on the $\mathrm{Ca}^{2+}$ pumping ATPase by increasing the maximal rate as well as the $\mathrm{Ca}^{2+}$ affinity of the ATPase. The phosphorylation sites are serine 16 and threonine 17 , catalyzed by cyclic AMP- and $\mathrm{Ca}^{2+}$-calmodulin-dependent proteinkinase, respectively $[14,15]$. Thus, there are two phosphorylation sites activating phospholamban and their stimulatory effects on the ATPase are additive. Similar additive effects of cyclic AMP and $\mathrm{Ca}^{2+}$ calmodulin dependent SL protein phosphorylation on the SL $\mathrm{Ca}^{2+}$ pumping ATPase have already been observed earlier [16].

\section{Alterations in SR $\mathrm{Ca}^{2+}$ Pump in the Pressure-Overloaded, Hypertrophied Heart}

In the mid-seventies many investigations were undertaken to correlate possible modifications of SL and SR function to the altered contractile properties of hypertrophied and failing hearts [17-20]. Myocardial hypertrophy was experimentally induced by various types of chronically increased workload such as aortic constriction, valvular insufficiency, and hypertension. A common observation in these studies was the reduced rate of ATP-dependent $\mathrm{Ca}^{2+}$ uptake in isolated SR membrane vesicles from hypertrophied hearts [21-23]. In the meantime it was firmly established that the $\mathrm{Ca}^{2+}$ pump in $\mathrm{SR}$ in vitro could be stimulated by cyclic AMP-dependent phosphorylation. Data on cyclic AMP levels in the hypertrophied myocardium were not available, but in one study it was hypothesized that the decreased $\mathrm{Ca}^{2+}$ accumulation in cardiac 


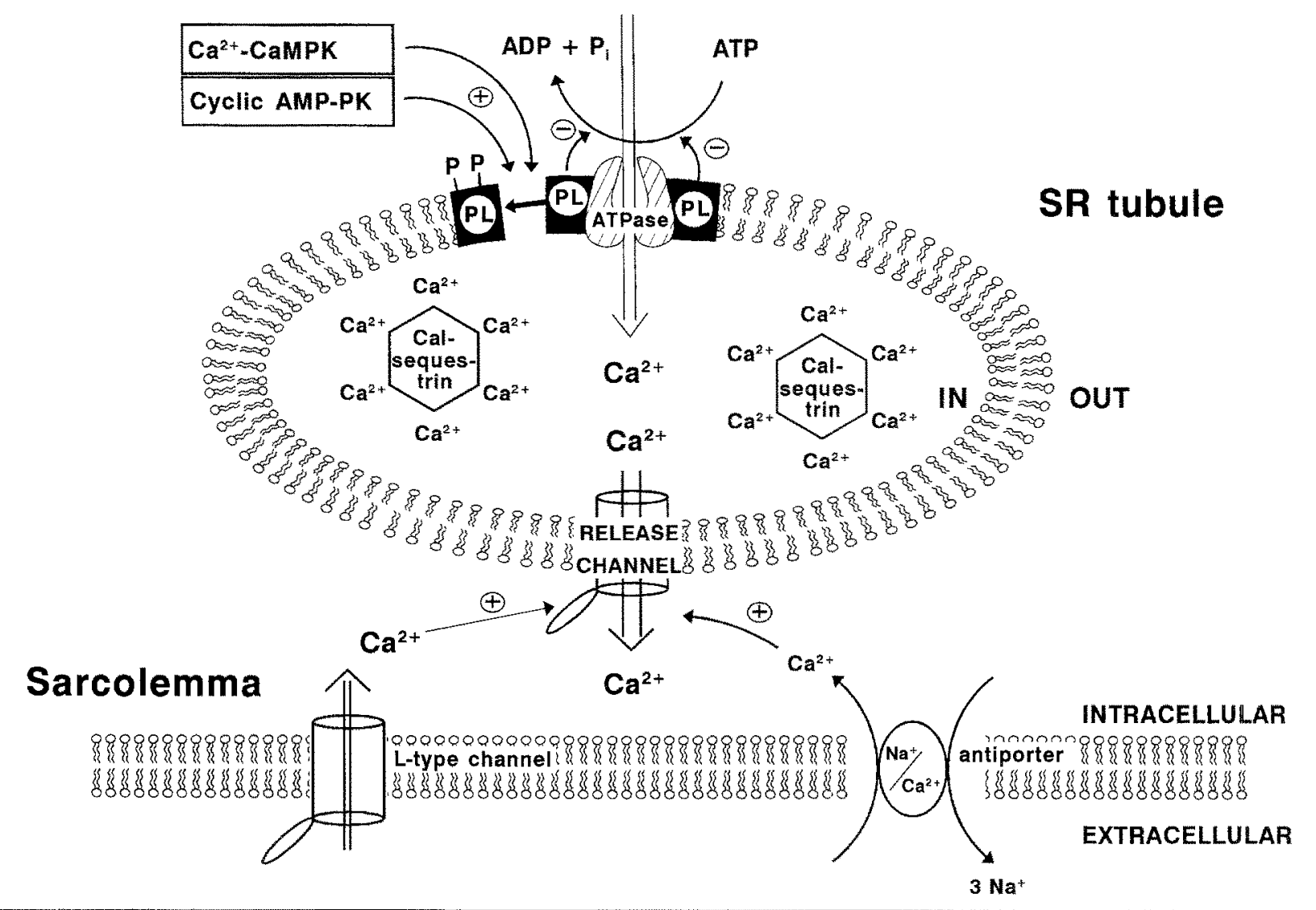

Fig. 1. Concerted operation of the second-messenger regulated $\mathrm{Ca}^{2+}$ pump and the $\mathrm{Ca}{ }^{\mathrm{z}+}$ release chonnel in SR and the depolanization-induced $\mathrm{Ca}^{2+}$ infux pathways through the SL. Notice the relative thickness of the arrows indicating the differences in amounts of $\mathrm{Ca}^{\mathrm{Z}+}$ moving during the phase of depolarization. Ca $\mathrm{a}^{2-}$ is actively transported into the $S R$ by the Ca ${ }^{z+}$ pump of which

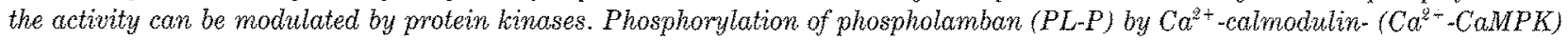
and cyclic AMP-(cyclic AMP-PK)-dependent protein kinases switches off the partial inhibition exerted on the Ca $a^{2+}$ pump by its unphosphorylated form (PL). The $\mathrm{Ca}^{2+}$ release channel is activated by a small rise in cystolic free $\mathrm{Ca}^{2+}$ originating from the depolarization-induced $\mathrm{Ca}^{2+}$ infus through the $L$-type $\mathrm{Ca}^{2+}$ channel and the $\mathrm{Na}^{+} / \mathrm{Ca}^{2+}$ antiporter in the $\mathrm{SL}$.

SR from spontaneous hypertensive rats was due to reduced cyclic AMP-dependent protein kinase activity [24]. This postulation prompted us to study the functional changes in microsomes from hypertrophied heart and to investigate whether these changes originate from an altered degree of phospholamban phosphorylation. Left ventricular hypertrophy was induced by clamping the aorta of rabbits for one month [25], in which period left ventricular mass increased 1.6 fold ( $p<0.01$ versus sham-operated animals). In vitro characterization of enriched SR membrane vesicles isolated from control and hypertrophied left ventricle are shown in Table 1 . The yield of SR vesicles from control and hypertrophied myocardium was similar for the control and the hypertrophied hearts. The activity of the SR marker-enzyme rotenon-insensitive $\mathrm{NADPH}$ cytochroom $\mathrm{c}$ reductase was measured as reference for the rate of $\mathrm{SR} \mathrm{Ca}^{2+}$ pumping. The specific activity of the $\mathrm{Ca}^{2+}$ pump proved to be markedly reduced during hypertrophy, whereas the activity of the marker enzyme rotenen-insensitive NADPH cy- tochroom c reductase remained relatively constant (Table 1). The decrease in $\mathrm{Ca}^{2+}$ uptake rate was not due to increased $\mathrm{Ca}^{2+}$ release channel activity during the in vitro incubation, because inclusion in the assays of the release channel inhibitor ruthenium red, did not alter the results [26]. Incubation of the SR membranes from control hearts with $10 \mu \mathrm{M}$ cyclic AMP, $50 \mu \mathrm{M}\left[\gamma^{32} \mathrm{P}\right]$ ATP and $2-6 \mathrm{mU} \cdot \mathrm{ml}^{-1}$ purified cyclic AMP-dependent protein kinase led to enhancement of the ${ }^{32} \mathrm{P}$ incorporation into SR proteins of which phospholamban was the predominant one [12]. Indeed, prior phosphorylation of SR proteins under the latter conditions increased the $\mathrm{Ca}^{2+}$ uptake rate by 1.4 fold in both the control and the hypertrophied hearts (Table 1). This finding indicated that an alteration in the phosphorylation degree of phospholamban was not re-

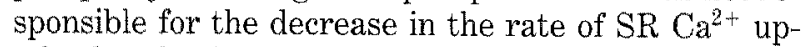
take by the hypertrophied heart. Likewise, it was shown that in the failing human heart, the second messenger control of SR $\mathrm{Ca}^{2+}$ ATPase was unaffected [27]. In a number of subsequent papers in which hu- 
Table 1. Yield, enzymatic and $\mathrm{Ca}^{2+}$ transport activities of enriched $S R$ membranes from control and hypertrophied rabbit hearts

\begin{tabular}{|c|c|c|c|}
\hline & $\mathrm{n}^{2}$ & Control & Hypertrophied \\
\hline $\begin{array}{l}\text { Yield } \\
\left.\text { (mg protein.g.tissue }{ }^{-1}\right)\end{array}$ & 5 & $1.46 \pm 0.18$ & $1.72 \pm 0.14$ \\
\hline $\begin{array}{l}\text { NADPH cyt } c \text { reductase } \\
\quad \text { (nmol.min. }{ }^{-1} \cdot \text { mg protein }^{-1}\end{array}$ & 5 & $8.17 \pm 0.11$ & $7.77=0.05$ \\
\hline 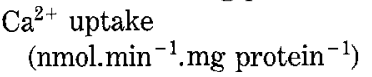 & & & \\
\hline control & 5 & $28.0 \pm 1.8$ & $19.5 \pm 1.0^{b}$ \\
\hline proteinkinase-treated & 5 & $37.5 \pm 2.6$ & $27.8 \pm 2.7^{b}$ \\
\hline $\begin{array}{l}{ }^{32} \mathrm{P} \text { incorporation } \\
\left(\text { pmol.mg protein }{ }^{-1}\right)\end{array}$ & & & \\
\hline control & 3 & 91 & - \\
\hline proteinkinase-treated & 3 & 423 & - \\
\hline
\end{tabular}

Left ventricular hypertrophy was produced in New Zealand white rabbits of either sex by constriction of the descending aorta as described before $[20,25]$. Briefly, the descending aorta at the level of the diaphragm was exposed through the abdominal cavity under anesthesia and sterile conditions. A clip was placed just proximal of the coeliac artery. When animals were killed after one month bodyweights of the sham-operated $(3.55 \pm 0.11 \mathrm{~kg})$ animals were not different from the animals with aorta constriction $(3.49 \pm 0.08$ $\mathrm{kg}$ ). But the left ventricle + septum weight (relative to the body weight) was significantly higher $(1.75 \pm 0.06$ versus $1.34 \pm 0.03$ fold) in the animals with aorta constriction. Enriched SR membranes were isolated from the left ventricle by differential centrifugation [25]. Analysis of rotenon-insensitive NADPH cyt $c$ reductase, ATPdependent $\mathrm{Ca}^{2+}$ uptake and ${ }^{32} \mathrm{P}$ ineorporation into total $\mathrm{SR}$ protein, was performed using spectrophotometry (wavelength $340 \mathrm{~nm}$ ), radioactively labelled ${ }^{45} \mathrm{Ca}$ and $\gamma_{-}{ }^{32} \mathrm{P}$-labelled ATP, respectively. For details of protein kinase treatment is referred to the text. Details of the incubation conditions for each enzymatic and transport assay can be found elsewhere [25]. ${ }^{a} \mathrm{n}=$ number of rabbits in each group and ${ }^{b} p<0.05$ versus control animals.

man, rabbit and rat hearts were studied [28-30], the unresolved issue of the cause of the reduction in the rate of $\mathrm{SR} \mathrm{Ca}^{2+}$ uptake rate during hypertrophy was readdressed. For instance, in severe myocardial hypertrophy, the concentration of the SR $\mathrm{Ca}^{2+}$ ATPase messenger RNA (mRNA) decreased to about $70 \%$ and that of the protein to $80 \%$ of the sham-operated animals, whereas the total left ventricular mRNA and $\mathrm{Ca}^{2+}$ ATPase protein was either unchanged or slightly increased [30]. Similarly, a marked decrease (up to about $50 \%$ of controls) in SR $\mathrm{Ca}^{2+}$ ATPase mRNA was found in human end-stage heart failure [29]. Since there are different isoforms of the SR $\mathrm{Ca}^{2+}$ ATPase and their expressions are specifically and developmentally regulated, some studies looked for possible changes in the expression pattern of isoforms at the mRNA level using $\mathrm{S} 1$ nuclear mapping analysis and specific cDNA probes for the rat heart SR $\mathrm{Ca}^{2+}$ ATPase mRNA. In one of these studies, the $5^{\prime}$-end sequence (1.1 kb fragment) and a 3 '-portion $(2.4 \mathrm{~kb}$ fragment) of the cardiac SR $\mathrm{Ca}^{2+}$ ATPase were shared by the normal and the pressure-overloaded hypertro- phied rat heart [30]. These data indicate that the same $\mathrm{Ca}^{2+}$ ATPase mRNA isoenzyme is expressed in both normal and hypertrophied rat myocardium. By using similar molecular biological techniques, it was demonstrated that the same SR $\mathrm{Ca}^{2+}$ ATPase is expressed in control and pressure-overload hypertrophied rabbit hearts [28]. Cardiac tissue, whether hypertrophied or normal, expresses the slow-twitch SR $\mathrm{Ca}^{2+}$ ATPase isoform (SERCA 2) [9,28,31]. Messenger RNA levels of SERCA 2 isoform of SR $\mathrm{Ca}^{2+}$ ATPase were decreased in failing hearts explanted from patients with a dilated cardiomyopathy who underwent a cardiac transplantation [9]. These results indicate that in severe myocardial hypertrophy induced by chronic pressure-overload, the decrease in the $\mathrm{SR} \mathrm{Ca}^{2+}$ pump activity is not due to an altered second messenger control or an isoenzyme shift. It is more likely that the expression of the SR $\mathrm{Ca}^{2+}$ ATPase gene does not follow the overall increase in gene expression that results in cardiac growth. The slower rate of expression of the SERCA 2 gene leads to a decrease in density of $\mathrm{Ca}^{2+}$ pump protein molecules embedded into the SR membrane and thus to an impaired $\mathrm{Ca}^{2+}$ handling of the hypertrophied myocardium.

\section{Alterations in the SR $\mathrm{Ca}^{2+}$ Pump Function in the Ischemic and "Stunned" Myocardium}

The effects of ischemia on SR $\mathrm{Ca}^{2+}$ pump and release channel have been previously studied with whole cardiac muscle homogenates and isolated SR vesicle fractions [32-38]. Assay of enzymatic activities in both tissue fractions suggested that $\mathrm{SR} \mathrm{Ca}^{2+}$ uptake and $\mathrm{Ca}^{2+}$ ATPase activities are impaired to a similar degree in the ischemic heart. Some of the loss was suggested to have occurred during membrane isolation or to be due to selection of a subpopulation of damaged SR vesicles [36]. However, in several studies parallel changes in $\mathrm{SR} \mathrm{Ca}^{2+}$ uptake rate in unfractionated homogenates and isolated $\mathrm{SR}$ vesicle fractions have been found, ruling out the possibility that assays were performed with selected SR vesicle populations [37,39]. $\mathrm{Ca}^{2+}$ release channel inhibitors (ryanodine and ruthenium red) were used to distinguish between ischemic damage to the $\mathrm{SR} \mathrm{Ca}^{2+}$ release channel and $\mathrm{SR} \mathrm{Ca}^{2+}$ pump. Periods of ischemia lasting $15 \mathrm{~min}$ and $60 \mathrm{~min}$ depressed oxalate-supported $\mathrm{SR} \mathrm{Ca}^{2+}$ pumping rates of rat heart homogenate by $50 \%$ and $80 \%$, respectively [39]. No decrease was observed, however, when the $\mathrm{Ca}^{2+}$ uptake rate was measured after $\mathrm{Ca}^{2+}$ release channel closure by ruthenium red or ryanodine [39]. Therefore it was assumed that ischemia primarily affects the function of the $\mathrm{Ca}^{2+}$ release channel, although more recent results do not support this hypothesis [40]. The decrease in SR $\mathrm{Ca}^{2+}$ uptake rate usually appears after $10-15 \mathrm{~min}$ of ischemia 
$[33,34,36]$. Such a brief period of ischemia does not lead to irreversible myocardial damage, but upon reperfusion, recovery of contractile function is delayed ("stunned myocardium") [5,7,41-45]. In the following paragraphs we present some data characterizing the $\mathrm{SR} \mathrm{Ca}^{2+}$ pump function in stunned myocardium.

\section{Myocardial stunning}

The molecular mechanisms contributing to myocardial stunning are poorly understood, but it is likely that the slow recovery of contractile function is based upon the slow recovery of ischemia-induced changes at molecular function levels. In a recent report, Opie described as the two likely causes of stunning during the very early reperfusion phase excess of cystolic $\mathrm{Ca}^{2+}$ and the formation of free radicals [49]. For instance, it was shown that intracoronary $\mathrm{Ca}^{2+}$ infusions during stunning could restore the contractility [47]. Krause et al. were the first to demonstrate in a canine model that SR membranes isolated from stunned canine myocardium had a decreased ability to actively transport $\mathrm{Ca}^{2+}$, which suggested a failure of $\mathrm{Ca}^{2+}$ handling at the level of the SR [7]. However, Kaplan et al. have recently shown, that neither an altered SR uptake of $\mathrm{Ca}^{2+}$ nor an abnormal function of $\mathrm{SR} \mathrm{Ca}^{2+}$ release channels contribute to the contractile dysfunction of stunned myocardium in rabbits [48]. Others have hypothetized that especially during the late reperfusion phase, a decreased $\mathrm{Ca}^{2+}$ sensitivity of myofilaments is involved in the contractile dysfunction, although mechanism(s) involved in the alteration of $\mathrm{Ca}^{2+}$ activation of contractile apparatus were not provided [5]. This hypothesis of decreased $\mathrm{Ca}^{2+}$ sensitivity is supported by a recent study from our laboratory in which we have shown that the $\mathrm{Ca}^{2+}$ sensitizing agent EMD 60263 , which is devoid of phosphodiesterase inhibitor properties, restored segment length shortening and mechanical efficiency of stunned porcine myocardium, while exerting a negligible effect on the not stunned myocardium [49].

In the porcine model of myocardial stunning (two periods of 10 min coronary artery occlusion separated by 30 min reperfusion) we and others have shown that reperfusion leads to the induction of several genes encoding proto-oncogenes [50,51], $\mathrm{Ca}^{2+}$ binding proteins [52] and heat shock proteins (HSPs) [45,53-59]. It has been observed that brief periods of myocardial ischemia and reperfusion do not only cause prolonged contractile dysfunction, but also increase the tolerance for irreversible damage during a subsequent sustained episode of ischemia ("ischemic preconditioning"). It is not yet clear whether the upregulation of these genes contribute to the molecular events involved in ischemic preconditioning. Evidence is accumulating that HSPs have a protective effect on the infaret size limitation which occurs when a long lasting coronary artery occlusion is separated from a brief period of ischemia by a period of $24 \mathrm{~h}$ [59]. Elevated levels of HSPs and ubiquitin are believed to have pro- tective/adaptive effects $[45,53]$. However, studies in mammalian cell cultures indicate that the increased synthesis of HSP-27 under conditions of severe stress lead to the disruption of cellular $\mathrm{Ca}^{2+}$ homeostasis [60]. In the present work (Figure 2 and $[52,65]$ ) the changes in $\mathrm{Ca}^{2+}$ pump function are evaluated in relation to the contractile dysfunction during myocardial stunning. Therefore, we examined in the normal and stunned myocardium the steady state mRNA levels of cardiac specific SR $\mathrm{Ca}^{2+}$-ATPase isoform in parallel with SR $\mathrm{Ca}^{2+}$ pump function of isolated SR membrane vesicles.

\section{Expression of $\mathrm{SR} \mathrm{Ca}^{2+}$-ATPase gene and $S R \mathrm{Ca}^{2+}$ uptake activity in stunned reperfused myocardium}

Cardiac specific SR $\mathrm{Ca}^{2+}$-ATPase mRNA expression pattern was measured by hybridizing the total RNA preparations derived from stunned $(90 \mathrm{~min})$ and not stunned myocardium. In stunned (E) myocardium mRNA expression of SR $\mathrm{Ca}^{2+}$-ATPase was significantly enhanced $(1.76 \pm 0.28$ assessed fold by densitometric analysis, $\mathrm{n}=4$ ) as compared to the not stunned myocardium (Figure 2). A single mRNA species $(3.7 \mathrm{~kb})$ migrating just below to the $28 \mathrm{~S}$ ribosomal RNA hybridized to the cardiac specific $\mathrm{SR} \mathrm{Ca}^{2+}$ ATPase cDNA probe [63]. No differences in mRNA levels were seen between stunned and not stunned tissue fractions obtained in experiments carried out with sham-operated animals [52]. Apart from the SR $\mathrm{Ca}^{2+}$-ATPase, other $\mathrm{Ca}^{2+}$ transport regulating proteins like phospholamban, calsequestrin and calmodulin also contribute to the maintenance of $\mathrm{Ca}^{2+}$ homeostasis $[2,4,13,18]$. In a detailed study on various $\mathrm{Ca}^{2+}$ binding proteins using the same porcine model, we have shown that $\mathrm{SR} \mathrm{Ca}^{2+}$-ATPase gene expression did not alter during the first sequence of $10 \mathrm{~min}$ occlusion and $30 \mathrm{~min}$ reperfusion. After the second occlusion-reperfusion sequence the $\mathrm{SR} \mathrm{Ca}^{2+}$-ATPase mRNA levels in stunned myocardium were even reduced but recovered during the further reperfusion period and reached maximal levels at $90 \mathrm{~min}$ [52]. The expression of glyceraldehyde-3-phosphate dehydrogenase (GAPDH), a house keeping gene, was used as a standard and to check the integrity of RNA as well as loading differences on the gel. As expected, GAPDH expression did not change during our stunning protocol or even decreased as reported earlier for more severe ischemia leading to myocardial infarction [62]. Hence, our data on the upregulation of $\mathrm{SR}-\mathrm{Ca}^{2+}$ ATPasae gene expression during late reperfusion may be an adaptive and temporary phenotypic alteration in the stunned myocardium [52]. The increased transcriptional activity of $\mathrm{SR} \mathrm{Ca}^{2+}$-ATPase suggests the presence of a repair process at the SR level in the stunned myocardium [64].

In order to compare the mRNA expression data with the SR $\mathrm{Ca}^{2+}$ pump function, we also examined ATP dependent $\mathrm{Ca}^{2+}$ uptake and cyclic AMP depen- 


\section{E C E C E C E} C E C E C E C E

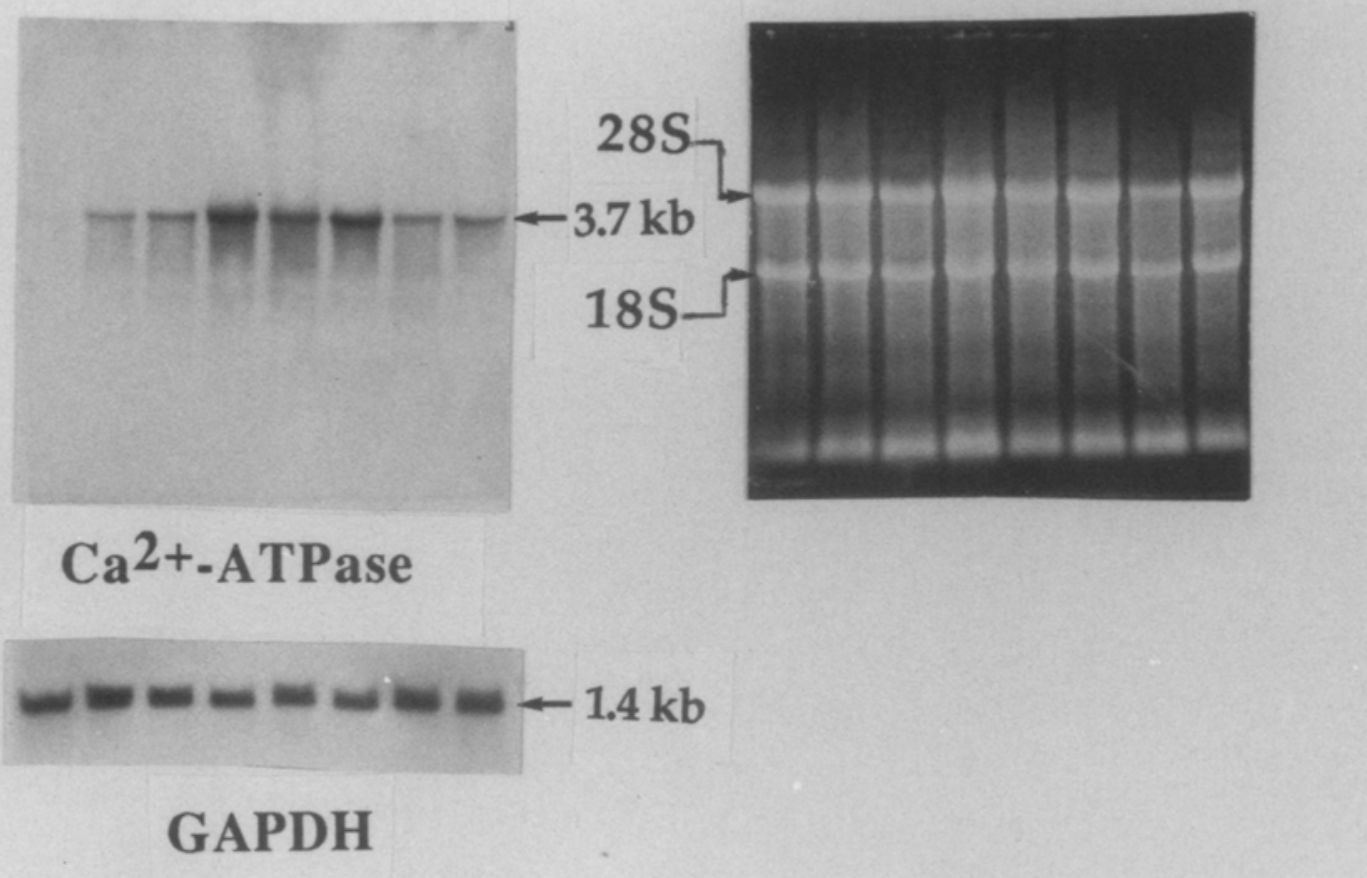

Fig. 2. Expression of SR Ca ${ }^{2+}$-ATPase gene in stunned and not stunned myocardium. Northern blot hybridization showing the expression of cardiac specific SR C $a^{2+}$-ATPase $m R N A$ signals in stunned (experimental, $E$ ) and not stunned (control, C) of four separate experiments. To induce stunning in pigs the left anterior decending coronary artery was oceluded for 10 min and reperfused for 30 min, then again occluded for 10 min and reperfused for 90 min. At the end of the second reperfusion (90 min) the pigs were sacrificed and myocardial tissues from the left anterior descending ( $E$ ) and left circumflex coronary artery (C) regions were excised and processed for Northern hybridization using rat specific cardiac SR Ca ${ }^{2+}$-ATPase cDNA probe. A single mRNA species of $3.7 \mathrm{~kb}$ was hybridized to the radioactive $c D N A$ probe [63]. On right panel ethidium bromide stained agarose gel is shown to depict the quality and quantity of total cellular RNA loaded on the gel. The lower panel shows the GAPDH signal (1.4 $\mathrm{kb})$ as a standard and to compare the induction of $C a^{2+}-A T P a s e$ gene in stunned $(E)$ vs not stumned $(C)$ myocardium.

dent phosphorylation of phospholamban in isolated SR membrane vesicles of stunned reperfused (30 $\mathrm{min})$ and not stunned regions. $\mathrm{Ca}^{2+}$ uptake by the SR was increased by $17 \%$ in the fractions isolated from stunned myocardium as compared to the control [65]. No differences in $\mathrm{Ca}^{2+}$ uptake rate were seen between stunned and not stunned tissue fractions obtained from sham-operated animals (not shown). In the presence of exogenous cyclic AMP dependent protein kinase the amount of ${ }^{32} \mathrm{P}$ incorporation into phospholamban remained unaltered in both ventricular regions [65]. Our results on SR $\mathrm{Ca}^{2+}$-ATPase mRNA levels and $\mathrm{SR} \mathrm{Ca}^{2+}$ uptake activity, although not measured at the same time of reperfusion (90 and $30 \mathrm{~min}$, respectively), strengthen our hypothesis that the $\mathrm{SR} \mathrm{Ca}^{2+}$ pump may temporarily be upregulated by a mechanism not related to its regulation by second messengers.

We also observed that phospholamban was not upregulated in stunned myocardium which indicates that the stoichiometric phospholamban $/ \mathrm{Ca}^{2+}$-ATPase subunit ratio favors a less inhibited state of the
SR $\mathrm{Ca}^{2+}$ pump [52]. In the same porcine model the steady-state tissue levels of mRNAs encoding protooncogenes [50,51], HSP-27, ubiquitin [45] and HSP-70 are enhanced [53]. Interestingly, $\alpha$ - and $\beta$-myosin heavy chain mRNA expressions did not alter in stunned myocardium in our porcine model [52], which suggests that repair processes occur predominantly at the membrane proteins. Our data support the hypothesis that brief episodes of ischemia cause adaptive alterations at the molecular level indicated by an enhanced transcriptional activity of stunned myocardium which may contribute to repair processes during recovery of contractile function.

Although the above described model does not lead to cell death [54], some reversible damage to intracellular $\mathrm{Ca}^{2+}$ transport regulatory proteins probably occurred, because we observed a compensatory increase of their mRNA expression [52]. These proteins could be targets of reversible injury which at the same time may play a crucial role in the restoration of contractile function. Upregulation of the SR $\mathrm{Ca}^{2+}$-ATPase gene 
in response to ischemia and reperfusion points toward its involvement in mechanisms underlying myocardial stunning. Furthermore, we also like to postulate that different stress conditions alter the expression pattern of several sets of genes, and their combined actions will influence the phenotype of cardiomyocytes during stunning.

\section{Conclusions}

We reviewed the available literature data on $\mathrm{SR} \mathrm{Ca}^{2+}$ pump mRNA levels and $\mathrm{Ca}^{2+}$ pump protein function in the chronically pressure-overloaded hypertrophied and post-ischemic stunned myocardium in the light of some new data of our laboratory. Results on pressureoverloaded hypertrophied myocardium provide convincing evidence that the impaired relaxation of the hypertrophied heart is likely due to a lower capacity of the SR to pump $\mathrm{Ca}^{2+}$ ions as a result of a lower density of $\mathrm{Ca}^{2+}$ pump protein molecules within the SR membrane. Apparently, the expression of the SR $\mathrm{Ca}^{2+}$-ATPase gene does not follow the overall increase in gene expression that results in cardiac hypertrophy, rather its expression declines. As far as the contractile dysfunction in ischemic and stunned myocardium is concerned the available data do not point toward a critical involvement of changes in the SR $\mathrm{Ca}^{2+}$ pump function during hypo-contractility. Surprisingly, we observed enhanced expression of the $\mathrm{Ca}^{2+}$-ATPase gene accompanied by a slight increase in the SR $\mathrm{Ca}^{2+}$ pump activity in stunned myocardium. It is therefore postulated that this increase is an adaptive response of the reversibly injured myocardium which may contribute to the slow process of recovery of contractile function.

\section{Acknowledgements}

Parts of this work were supported by grant nr. 92.308 from the Netherlands Heart Foundation.

\section{References}

1. Morgan JP. Abnormal intracellular modulation of calcium as a major cause of cardiac contractile dysfunction. $N$ Engl J Med 1991;325:625-631.

2. Opie LH. Intracellular $\mathrm{Ca}^{2+}$ fluxes and sarcoplasmatic reticulum. In: The heart: Physiology and metabolism (Opie LH, Ed.), Raven Press, New York, 1991:127-146.

3. Stern MD, Lakatta EG. Excitation-contraction coupling in the heart: the state of the question. FASEB J 1992;6: 3092-3100.

4. Carafoli $\mathrm{E}$. The homeostasis of calcium in heart cells. $J \mathrm{Mol}$ Cell Cardiol 1985;17:203-212.

5. Marban E. Myocardial stunning and hibernation. The physiology behind the colloquialisms. Circulation 1991;83:681688.

6. Nayler WG. Calcium, calcium antagonists, stunning, and hibernation: an overview. Cardiovasc Drugs Ther 1991;5: 227-233.
7. Krause SM, Jacobus WE, Becker LC. Alterations in cardiac sarcoplasmic reticulum calcium transport in the postischemic "stunned" myocardium. Circ Res 1989;65:526-530.

8. Katz AM. Cardiomyopathy of overload. A major determinant of prognosis in congestive heart failure. $N \mathrm{EnglJ} \mathrm{Med}$ 1990;322:100-110.

9. Arai M, Alpert NR, McLennan DH, Barton P, Periasamy M. Alterations in sarcoplasmic reticulum gene expression in human heart failure. A possible mechanism for alteration in systolic and diastolic properties of the failing myocardium. Circ Res 1993;72:463-469.

10. Meerson FZ, Kapelko VI, Nourmatov AA. Physiological evaluation of the capacity of the diastole mechanism. Acta Cardiol 1971;26:547-567.

11. Grossman W, Lorell BH. Diastolic relaxation of the heart: basic research and current applications for clinical cardiology. Boston, Martinus Nijhoff, 1988.

12. Tada M, Katz AM. Phosphorylation of the sarcoplasmic reticulum and sarcolemma. Ann Rev Physiol 1982;44:401-423.

13. Lamers JMJ. Calcium transport systems in cardiac sarcolemma and their regulation by the second messengers cyclic $\mathrm{AMP}$ and $\mathrm{Ca}^{2+}$-calmodulin. Gen Physiol Biophys 1985;4: 143-154.

14. Sasaki T, Inui M, Kimura Y, Kuzuya T, Tada M. Molecular mechanism of regulation of $\mathrm{Ca}^{2+}$ pump ATPase by phospholamban in cardiac sarcoplasmic reticulum. Effects of synthetic phospholamban peptides on $\mathrm{Ca}^{2+}$ pump ATPase. $J$ Biol Chem 1992;267:1674-1679.

15. James P, Inui M, Tada M, Caiesi M, Carafoli E. Nature and site of regulation of the $\mathrm{Ca}^{2+}$ pump of sarcoplasmatic reticulum. Nature 1989;342:90-92.

16. Lamers JMJ, Stinis JT, De Jonge HR. On the role of cyclic $\mathrm{AMP}$ and $\mathrm{Ca}^{2+}$-calmodulin-dependent phosphorylation in the control of $\left(\mathrm{Ca}^{2+}+\mathrm{Mg}^{2+}\right)$ ATPase of cardiac sarcolemma. FEBS Lett 1981;127:139-144.

17. Katz AM. Congestive heart failure: Role of altered myocardial cellular control. $N$ Engl J Med 1979;293:1184-1191.

18. Dhalla NS, Das PK, Sharma GP. Subcellular basis of cardiac contractile failure. J Mol Cell Cardiol 1978;10:363-385.

19. Sehwartz LA, Sordahl LA, Entman ML, et al. Abnormal biochemistry in myocardial failure. Am J Cardiol 1973;32: 407-422.

20. Lamers JMJ, Stinis JT, Kort WJ, Hülsmann WC. Biochemical studies on the sarcolemmal function in the hypertrophied rabbit heart. J Mol Cell Cardiol 1978;10:235-248.

21. Sordahl LA, Collum WBM, Wood WG, Schwartz A. Mitochondria and sarcoplasmic reticulum function in eardiae hypertrophy and failure. Am J Physiol 1973;224:497-502.

22. Tomlinson CW, Lee SL, Dhalla NS. Abnormalities in heart membranes and myofibrils during bacterial infective cardiomyopathy in the rabbit. Circ Res 1976;39:82-92.

23. Ito $\mathrm{Y}$, Suko J, Chidsey CA. Intracellular calcium and myocardial contractility v. calcium uptake of sarcoplasmic reticulum fraction in hypertrophied and failing hearts. $J \mathrm{Mol} \mathrm{Cell}$ Cardiol 1974;6:237-247.

24. Limas CJ, Cohn JN. Defective calcium transport by cardiac sarcoplasmic reticulum in spontaneously hypertensive rats. Circ Res 1977;40:162-I69.

25. Lamers JMJ, Stinis JT. Defective calcium pump in the sarcoplasmic reticulum of the hypertrophied rabbit heart. Life Sci 1979;24:2313-2320.

26. Feher JJ, Lebolt WR. Stabilization of rat cardiac sarcoplasmic reticulum $\mathrm{Ca}^{2+}$ uptake activity and isolation of vesicles with improved $\mathrm{Ca}^{2+}$ uptake activity. Mol Cell Biochem $1990 ; 90: 41-52$. 
27. Movsesian MA, Colyer J, Wang JH, Krall J. Phospholamban-mediated stimulation of $\mathrm{Ca}^{2+}$ uptake in sarcoplasmic reticulum of failing hearts. J Clin Invest 1990;85:1698-1702.

28. Nagai R, Zarain-Herzberg A, Brandl CJ, et al. Regulation of myocardial $\mathrm{Ca}^{2+}$-ATPase and phospholamban mRNA expression in response to pressure-overload and thyroid hormone. Proc Natl Acad Sci 1989;86:2966-2970.

29. Mercadier JJ, Lompré AM, Duc P, et al. Altered sarcoplasmic reticulum $\mathrm{Ca}^{2+}$-ATPase gene expression in the human ventricle during end-stage heart failure. $J$ Clin Invest 1990; 85:305-309.

30. De la Bastie D, Levitski D, Rappaport L, et al. Function of the sarcoplasmic reticulum and expression of its $\mathrm{Ca}^{2+}$ ATPase gene in pressure overload-induced cardiac hypertrophy in the rat. Circ Res 1990;66:554-546.

31. Komura I, Kurabayashi M, Shibazaki Y, Takaku F, Yazaki $\mathrm{Y}$. Molecular cloning and characterization of a $\mathrm{Ca}^{2+}+\mathrm{Mg}^{2+}$ dependent adenosine triphosphatase from rat cardiac sarcoplasmic reticulum. Regulation of its expression by pressure overload and developmental stage. J Clin Invest 1989;83: 1102-1108.

32. Dhalla NS, Panagia V, Singal PK, Makino N, Dixon IMC, Eyolfson DA. Alterations in heart membrane calcium transport during development of ischemia-reperfusion injury. $J$ Mol Cell Cardiol 1988;20(Suppl. II):3-13.

33. Krause S, Hess ML. Characterization of cardiac sarcoplasmic reticulum function during short-term normothermic global ischemia. Circ Res 1984;55:176-184.

34. Murphy ML, Peng CF, Kane JJ, Strauss KD. Ventricular performance and biochemical alteration of regional ischemic myocardium after reperfusion in the pig. Am $J$ Cardiol 1982;50:821-828.

35. Schoutsen B, Blom JJ, Verdouw PD, Lamers JMJ. Calcium transport and phospholamban in sarcoplasmic reticulum of ischemic myocardium. $J$ Mol Cell Cardiol 1989;21:719-727.

36. Rapundalo ST, Briggs FN, Feher JJ. Effects of ischemia on the isolation and function of canine cardiac sarcoplasmic reticulum. J Mol Cell Cardiol 1986;18:837-851.

37. Limbruno U, Zuechi R, Ronga-Testoni S, Galboni P, Ronea G, Merioni M. Sarcoplasmic reticulum function in the "stunned" myocardium. J Mol Cell Cardiol 1989;21:10631072 .

38. Konno N, Yanagishita T, Geshi E, Karagiri T. Degradation of cardiac sarcoplasmic reticulum in acute myocardial ischemia. Jpn Circ J 1987;51:411-420.

39. Feher JJ, Lebolt WR, Mason DH. Differential effect of global ischemia on the ryanodine-sensitive and ryanodineinsensitive calcium uptake of cardiac sarcoplasmic reticulum. Circ Res 1989;65:1400-1408.

40. Darling EM, Lai FA, Meissner G. Effects of regional ischemia on the ryanodine-sensitive $\mathrm{Ca}^{2+}$ release $\mathrm{Ca}^{2+}$ channel of cardiac sarcoplasmic reticulum. J Mol Cell Cardiol 1992; 24:1179-1188.

41. Jennings R, Schaper J, Hill M, Steenbergen C, Reimer K. Effect of reperfusion late in the phase of reversible ischemic injury. Circ Res 1985;56:262-271.

42. Bolli R. Mechanisms of myocardial stunning. Cireulation 1990;82:723-738.

43. Schaper W. Molecular mechanisms in "stunned myocardium." Cardiovasc Drugs Ther 1991;5:925-932.

44. Kusuoka H, Marban E. Cellular mechanisms of myocardial stunning. Annu Rev Physiol 1992;54:243-256.

45. Andres J, Sharma HS, Knöll R, et al. Expression of heat shock proteins in the normal and stunned porcine myocardium. Cardiovasc Res 1993;27:1421-1429.
46. Opie LH. Meeting Report-The current status of stunning, hibernation, and preconditioning. Cardiovasc Res 1993;27: 886-890.

47. Ito $B$, Tate H, Kobayashi M, Schaper W. Reversible injured, post-ischemic canine myocardium retains normal contractile reserve. Circ Res 1987;61:834-846.

48. Kaplan P, Hendrikx M, Mattheussen M, Mubagawa K, Flameng W. Effect of ischemia and reperfusion on sarcoplasmic reticulum $\mathrm{Ca}^{2+}$ uptake. Circ Res 1992;17:1123-113.

49. Soei LK, Sassen LMA, Fan DS, Van Veen T, Krams R, Verdouw PD. Myofibrillar $\mathrm{Ca}^{2+}$ sensitization predominantly enhances function and mechanical efficiency of stunned myocardium. Circulation 1994, in press.

50. Sharma HS, Brand T, Rohmann S, Schaper W. Myocardial stunning leads to the induction of c-fos and c-myc oncogenes in swine. Eur J Cell Biol 1990;52:24.

51. Brand T, Sharma HS, Fleischmann K, et al. Proto-oncogene expression in porcine myocardium subjected to ischemia and reperfusion. Circ Res 1992;71:1351-1360.

52. Frass O, Sharma H, Knöll R, et al. Enhanced gene expression of $\mathrm{Ca}^{2+}$ regulatory proteins in stunned porcine myocardium. Cardiovasc Res 1993;27:2037-2043.

53. Sharma HS, Snoeckx LHEH, Sassen LMA, et al. Expression and immunohistochemical localization of heat shock protein-70 in preconditioned porcine myocardium. Ann NY Acad Sci 1994; in press.

54. Schott R, Rohmann S, Braun E, Schaper W. Ischemic preconditioning reduces infarct in swine myocardium. Circ Res 1990;66:1133-1142.

55. Jentsch S. Ubiquitin-dependent protein degradation: a cellular perspective. Trends in Cell Biology 1992;2:98-103.

56. Schlesinger M. Heat shock proteins. J Biol Chem 1990;265: 12111-12114.

57. Yellon D, Latchman DS. Stress proteins and myocardial proteins. J Mol Cell Cardiol 1992;24:113-124.

58. Knowlton A, Brecher P, Apstein C, Ngoy S, Romo G. Rapid expression of heat shock protein in the rabbit after brief cardiac ischemia. $J$ Clin Invest 1991;87:139-147.

59. Marber MS, Latchman DS, Walker JM, Yellon DM. Cardiac stress proteins elevation $24 \mathrm{~h}$ after brief ischemia or heat stress is associated with resistance to myocardial infarction. Circulation 1993;88:1264-1272.

60. Chretien P, Landry J. Induction of Hsp27 phosphorylation and thermoresistance in Chinese hamster cells by arsenide, cycloheximide, A23187, and EDTA. Radiat Res 1990;121: $320-327$.

61. Harigaya S, Schwartz A. Rate of calcium binding and uptake in normal and failing human cardiac muscle. Circ Res 1969;25:781-794.

62. Sharma HS, Ullmann C, Schaper W. Molecular cloning and sequencing of a cDNA encoding glyceraldehyde-3-phosphate dehydrogenase from pig heart. $Z$ Kardiol 1992;81(Suppl 1):89.

63. Lompré AM, De la Bastie D, Boheler KR, Schwartz K. Characterization and expression of the rat heart sarcoplasmic reticulum $\mathrm{Ca}^{2+}$-ATPase mRNA. FEBS Lett 1989;249: $35-41$.

64. Knöll R, Andres J, Mohri M, Arras M, Schaper W, Sharma HS. Myocardial stunning and gene expression: Analysis by nuclear run-on assays. J Mol Cell Cardiol 1992;24(Suppl $\mathrm{V}): \mathrm{S} 75$.

65. Lamers JMJ, Duncker DJ, Bezstarosti K, McFalls EO, Sassen LMA, Verdouw PD. Increased activity of the sarcoplasmic reticular calcium pump in porcine stunned myocardium. Cardiovasc Res 1993;27:520-524. 